\title{
Optimization of cosmetic formulations development using Box-Behnken design with response surface methodology: physical, sensory and moisturizing properties
}

\author{
Daiane Garcia Mercurio', Lívia Salomão Calixto', \\ Patrícia Maria Berardo Gonçalves Maia Campos ${ }^{\circledR 1 *}$ \\ ${ }^{1}$ School of Pharmaceutical Sciences of Ribeirao Preto, University \\ of São Paulo, Ribeirão Preto, SP - Brazil
}

\begin{abstract}
Considering the importance of an adequate composition of the formulation in the development of stable, safe and effective cosmetic products, experimental design techniques are tools that can optimize the formulation development process. The objective of this study was to develop topical formulations using the Box-Behnken design with response surface methodology and evaluate its physical, sensory and moisturizing properties. The experimental design used in the first step allowed to identify and to quantify the influence of raw materials, as well as the interaction between them. In the second step, the analysis identified the influence of soy lecithin, the phytantriol and capric acid triglyceride and caprylic on the consistency index, stickiness and greasiness and skin hydration. Cetearyl alcohol, dicetyl phosphate and cetyl phosphate $10 \mathrm{EO}$ and acrylates/C10-30 alkylacrylate crosspolymer showed effects in rheological parameters. The addition of soy lecithin had significant effects in terms of consistency index, stickiness, oiliness and immediate moisturizing effects. Phytantriol showed effects on increasing consistency index and oiliness sensation. Thus, the experimental design was shown to be an effective tool for research and development of cosmetics, since it allowed the assessment of the individual and interaction effects of raw materials in the responses: rheological parameters, sensory and clinical efficacy.
\end{abstract}

Keywords: Emulsions. Formulation. Stability. Skin barrier. Experimental design.

\section{INTRODUCTION}

The process of cosmetic skin care formulations development involves detailed research and careful selection of raw materials. In this step, properties as stability, $\mathrm{pH}$ of the active ingredients, sensory characteristics, interactions between ingredients and

\footnotetext{
*Correspondence: P. M. B. G. Maia Campos. Departamento de Ciências Farmacêuticas. Faculdade de Ciências Farmacêuticas de Ribeirão Preto. Universidade de São Paulo. Avenida do Café, s/n - Monte Alegre - 14040-903 - Ribeirão Preto - SP, Brasil. Phone/Fax number: +55 16 33154307/36257202. E-mail: pmcampos@usp.br. E-mail address of each author: daiane.mercurio@gmail.com, liviascalixto@gmail.com, pmcampos@usp.br
}

the selection of biocompatible raw materials according to the skin type, should be taken into account (Calixto, Maia Campos, 2017).

Considering the importance of the adequate composition on the developments of cosmetic formulations, the experimental design is a significant tool as it allows the analysis of many variables, called factors, of a productive process, and allows to obtain a higher number of information using a smaller number of experiments (Costa-Machado, Bastos, de Freitas, 2013; Ferreira et al 2007; Tacon, Freitas, 2013).

Among the experimental design methods usually employed, factorial design is the most appropriate 
for the study of the effects of two or more influence variables. Examples of experimental planning are full and fractional factorial design. In factorial design, all the factors studied vary in a constant and planned way (Edwards, Mee, 2011).

With full factorial design, all possible combinations between the different factors are performed. Fractional factorial design optimizes the number of experiments without decrease the quantity and quality of information critical to the analysis, thus being faster and more economical. Fractional factorial design is used when the complete relation of these factors in the answers obtained is not already known and the number of factors studied is large (Neto, Scarminio, Bruns, 2010).

The choice of the design that best fits the experimental conditions of the study is a decisive step in the development of the method. Box-Behnken-type factorial design is indicated with the aim of using a response surface methodology in a three-factor threefactor study. Box-Behnken design is an independent quadratic model where all points of the design are either in the center of the drawing or centered on the ends of the cube, equidistant from the center (Edwards, Mee, 2011; Ferreira et al., 2007).

Box-Behnken planning does not contain all the possible combinations between the different factors, which contributes to the accomplishment of a smaller number of experimental tests and avoids unnecessary experiments under extreme conditions, which could give unsatisfactory results (Pereira, 2015).

Response surface methods are used to examine the relationship between a response and a series of quantitative experimental variables or factors. These methods are often used after having identified controllable factors and can find factor configurations that optimize the response (Calixto, Infante, Maia Campos, 2018). Physical stability is the property that cosmetic products present to maintain their physical characteristics such as color, odor, texture, consistency, feel to the touch and rheological behavior unchanged after the manufacturing process (Calixto, Maia Campos, 2017). For this, the determination of rheological behavior of the formulation, which assists in the evaluation of the performance of the final product during the application, as well as the evaluation of the physical nature of the vehicle is emphasized, making it possible to detect early signs of physical instability, facilitating the quality control of the constituents of the formulation and the final products (Guaratini, Gianeti, Maia Campos, 2006; Manço et al, 2015).
Among the main parameters evaluated through the rheological study, it was included the minimum apparent viscosity, flow and consistency indexes and thixotropy. The accompaniment of these characteristics over time allows to control the quality of the finished product and also to evaluate the effects of the product during the storage period (Manço et al, 2015; Gaspar, Maia Campos, 2003).

In this context, the aim of the present study was to develop cosmetic formulations in two phases using a Box-Behnken factorial design. For this, the design of experiments was performed in both phases of the development to characterize and to optimize the formulations according to the desired parameters. Thus, the 3-factor, 3-level experiment with surface response methodology (SRM) evaluated the effect of the raw materials phytantriol, soy lecithin, and caprylic/capric triglycerides on rheological, sensorial and hydration behavior of the developed formulations.

\section{MATERIAL AND METHODS}

In the present study, 3-level 3-factor Box-Behnken design with response surface methodology was applied to evaluate the main effects and interactions of formulation variables in cosmetic formulations. The experimental design and the analysis of results were performed using Minitab Software 16. Significant parameters were established with $\mathrm{p}<0.05$ and the parameters that showed significance level higher than 0.05 were neglected. Thus, the response of the independent variables in the three factors design takes the form of the equation 1 ,

$y=b_{0}+\sum_{i=1}^{k} b_{i} x_{i}+\sum_{i=1}^{k} b_{i} x_{i}^{2}+\sum_{i=1}^{k-1} \sum_{j>i}^{k} b_{j} x_{i} x_{j}+e$

where $\mathrm{Xi}$ are the studied factors that influence the response $Y, \beta 0$ is the constant, $\beta i$ is the linear coefficient, $\beta \mathrm{ii}$ is the quadratic coefficient and $\beta \mathrm{ij}(\mathrm{i} \neq \mathrm{j})$ is the linear interaction between $\mathrm{Xi}$ and $\mathrm{Xj}$.

Formulations were developed using cetearyl alcohol, dicetyl phosphate and cetyl phosphate $10 \mathrm{EO}$, acrylates/C10-30 alkyl acrylate crosspolymer, steareth-2 and steareth-21, octyl stearate, butylhydroxytoluene, butylene glycol, glycerin, disodium EDTA, cyclomethicone, cyclomethicone (and) dimethicone crosspolymer, phenoxyethanol and parabens. 
The development of the formulations was divided into two phases:

Phase 1-Study of the effects and optimization of the concentration of the self-emulsifying wax, hydrophilic polymer and proportion of nonionic surfactants.

Phase 2 - Study of the effects and optimization of the concentration of soy lecithin, phytantriol and caprylic/capric triglycerides.

The full factorial design was utilized in all phases of the development to characterize and optimize of the formulations according to the desired parameters.

\section{Study of the effects and optimization of the concentration of the self- emulsifying wax, hydrophilic polymer and proportion of nonionic surfactants}

In this phase, the Box-Behnken design was used for the characterization of the effects and to assist the determination of the raw materials concentrations of cetearyl alcohol, dicetyl phosphate and cetyl phosphate 10 EO, acrylates/C10-30 alkyl acrylate crosspolymer, and the proportion of the tensoactives steareth- 2 and steareth-21.

The minimum, medium and maximum concentrations of the raw materials were defined according to the information in the literature and technical information of the manufacturer. The objective was to evaluate the rheological behavior of the developed formulations. The levels used for factor encoding are shown in Table I.

TABLE I- Factors studied in Box-Behnken design and their +1 , $0,-1$ levels at phase I

\begin{tabular}{|c|c|c|c|c|}
\hline & \multirow{2}{*}{$\begin{array}{c}\text { Factors } \\
-1\end{array}$} & \multicolumn{3}{|c|}{ Levels } \\
\hline & & 0 & +1 & \\
\hline$X_{1}$ & $\begin{array}{l}\% \text { of cetearyl alcohol, } \\
\text { dicetyl phosphate and } \\
\text { cetyl phosphate } 10 \mathrm{EO}\end{array}$ & 1 & 2,5 & 4 \\
\hline$X_{2}$ & $\begin{array}{c}\% \text { of acrylates } / \mathrm{C} 10-30 \text { alkyl } \\
\text { acrylate crosspolymer }\end{array}$ & 0,2 & 0,3 & 0,4 \\
\hline$X_{3}$ & $\begin{array}{l}\text { Proportion steareth-21/ } \\
\text { steareth-2 }\end{array}$ & $30: 70$ & $50: 50$ & $70: 30$ \\
\hline
\end{tabular}

According to the concentrations proposed by the statistical software, 15 formulations were elaborated, that is, 15 experiments combining the different levels. The formulations were added with $0.5 \%$ retinyl palmitate, or $5 \%$ tocopheryl acetate, or $1 \%$ tocoretinate, resulting in 60 formulations.

\section{Rheological behavior}

The rheological behavior of the 60 formulations was evaluated in triplicate in a Brookfield DV-III digital cone and plate, rheometer (Brookfield Inc, USA) equipped with a CP52 spindle (Gaspar, Maia Campos, 2003). The curves were adjusted according to the Ostwald model to obtain the flow index and consistency index (Wagemaker et al, 2014). This analysis also provided viscosity and thixotropy data.

\section{Particle size distribution by dynamic light scattering (DLS)}

The determination of the droplet size of the formulations studied containing Tocoretinate was performed with the equipment LS 131320 Particle Size Analyzer, Beckman Coulter ${ }^{\circledR}$, to obtain the particle size distribution.

\section{Study of the effects and optimization of the concentration of soy lecithin, phytantriol and caprylic/capric triglycerides.}

In this phase, a new Box-Behnken factorial design was carried out to the characterization of the effects and to help the determination of adjuvant substances concentration on the formulations already developed in phase 1 in order to provide them additional benefits. The factorial design was performed to evaluate the effect of phytantriol, soy lecithin and caprylic/capric triglycerides on rheological, sensory and hydration behavior of the formulations developed.

Pursuant to the concentrations proposed by the statistical software, 15 formulations were elaborated. The levels used for factor encoding are shown in Table II. These formulations were evaluated for rheological behavior, immediate moisturizing effect and sensory characteristics. The experimental design and analysis of results were performed using Minitab ${ }^{\circledR} 16$ software (Minitab Inc., State College, PA). 
TABLE II - Factors studied in Box-Behnken design and their $+1,0,-1$ levels at phase II

\begin{tabular}{lllll}
\hline & Factors & \multicolumn{3}{c}{ Levels } \\
\cline { 3 - 5 } & -1 & 0 & +1 \\
\hline $\mathrm{X}_{4}$ & \% of phytantriol & 0 & 1,5 & 3 \\
$\mathrm{X}_{5}$ & $\begin{array}{c}\text { \% of soy lecithin } \\
\text { \% of caprylic/capric } \\
\text { triglycerides }\end{array}$ & 0 & 1,5 & 3 \\
$\mathrm{X}_{6}$ & 0 & 2,5 & 5 \\
\hline
\end{tabular}

\section{Rheological behavior}

The study of the rheological behavior was performed on all formulations in triplicate, using a Brookfield DV-III digital cone and plate, rheometer (Brookfield Inc, USA) equipped with a CP52 spindle (Gaspar, Maia Campos, 2003). The curves were adjusted according to the Ostwald model to obtain the flow index and consistency index (Wagemaker et al, 2014). This analysis also provided viscosity and thixotropy data.

\section{Immediate moisturizing effect}

In order to evaluate the moisturizing effect, the stratum corneum water content was measured before and after three hours of application of $2 \mu \mathrm{g} / \mathrm{cm}^{2}$ of the formulations. For this, an immediate efficacy study was carried out with 10 volunteer's forearms. Five measurements were performed in each study region with the Corneometer CM 825 equipment and the mean values were calculated. Afterwards, the final value / initial value ratio was calculated for the statistical analysis (Gianeti, Mercurio, Maia Campos, 2013; Maia Campos et al, 2014).

\section{Sensory analysis}

The sensory evaluation was performed with the application of $300 \mu \mathrm{L}$ of the formulations under study in a circular region with $5 \mathrm{~cm}$ in diameter in the forearm of 10 volunteers. The formulations were evaluated for the oily sensation and stickiness parameters. These characteristics were evaluated on a scale from 0 to 10 , where 0 means low intensity of the parameter and 10 high intensity (Manço et al, 2015).

\section{RESULTS AND DISCUSSION}

Few studies have been found in the literature using factorial design of experiments in cosmetic development area. Recently, Berthele et al. (2014) used experimental design to optimize the antimicrobial efficacy of cosmetic formulations. The optimum composition of the coemulsifier mixture was also studied using experimental design with the analysis of the parameters: rheological behavior, centrifugation test, specific conductivity and $\mathrm{pH}$ value measurement (Djuris et al., 2014).

The performance and acceptance of many dermocosmetic products are related to the rheological behavior of the product (Calixto, Maia Campos, 2017; Calixto, Infante, Maia Campos, 2018; Gianeti et al., 2012; Jiao, Burgess, 2003). The study of the rheological behavior of a formulation and the effect of raw materials on this property is very important for the choice of appropriate packaging in the manufacturing process involving shaking and transfer as well as in transport and storage situations.

\section{PHASE 1: FIRST BOX-BEHNKEN FACTORIAL DESIGN ANALYSIS AND PARTIAL RESULTS}

\section{Statistical analysis for consistency index (IC)}

In the first phase of development, the use of the response surface methodology, allows the study of the effects raw materials on the rheological behavior and the particle size of the formulations developed.

Equations 2-5 represent the adjusted models obtained from statistical analysis that relates the response, consistency index (CI), and the significant encoded factors $\mathrm{X}_{1}=$ cetearyl alcohol, dicetyl phosphate and cetyl phosphate $10 \mathrm{EO}, \mathrm{X}_{2}=$ acrylates $/ \mathrm{C} 10-30$ alkyl acrylate crosspolymer and $\mathrm{X}_{3}$ "proportion of nonionic surfactants".

$$
\mathrm{IC}_{\mathrm{V}}=29037+7410 \mathrm{X}_{1+} 10518 \mathrm{X}_{2}-11488,8 \mathrm{X}_{1}^{2}
$$

$\mathrm{IC}_{\mathrm{A}}=28407,7+6455 \mathrm{X}_{1+} 11140,5 \mathrm{X}_{2}-9908,7 \mathrm{X}_{1}^{2}+4507,8 \mathrm{X}_{2}^{2}$ 
$\mathrm{IC}_{\mathrm{E}}=35645+5846,3 \mathrm{X}_{1+} 12358,1 \mathrm{X}_{2}-14774,6 \mathrm{X}_{1}^{2}$

$\mathrm{IC}_{\mathrm{T}}=31371+6904 \mathrm{X}_{1+} 11116,4 \mathrm{X}_{2}-10618,6 \mathrm{X}_{1}^{2}$

The factors " $\%$ of self-emulsifying wax" and " $\%$ of hydrophilic polymer" were significant, affecting linearly the response under study. The factor "proportion of nonionic surfactants" did not provide significant results for the response under analysis. Moreover, for all the formulations studied, the factor "cetearyl alcohol, dicetyl phosphate and cetyl phosphate 10 EO" had a negative quadratic effect. By means of the coefficients of the obtained equations, it was observed that $\mathrm{X}_{2}$ presents a more pronounced effect for the studied response than $X_{1}$. The effects of the factors studied can also be observed with graphics obtained by the response surface method from equations 2-5 (Figure 1).
(A)

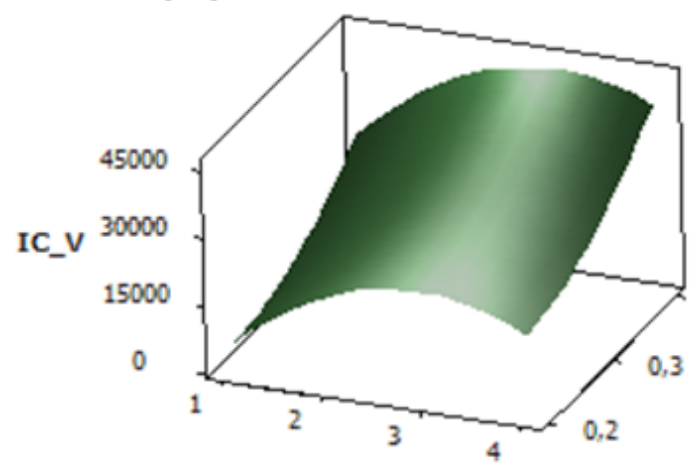

$\%$ Self-emulsifying wax

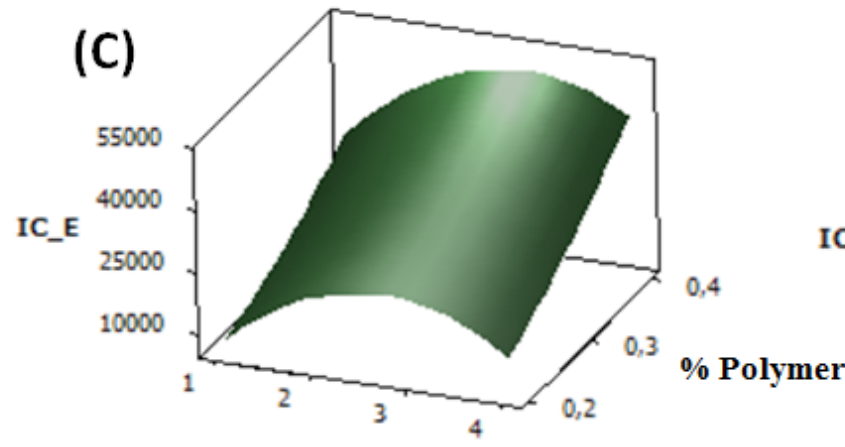

$\%$ Self-emulsifying wax
(B)

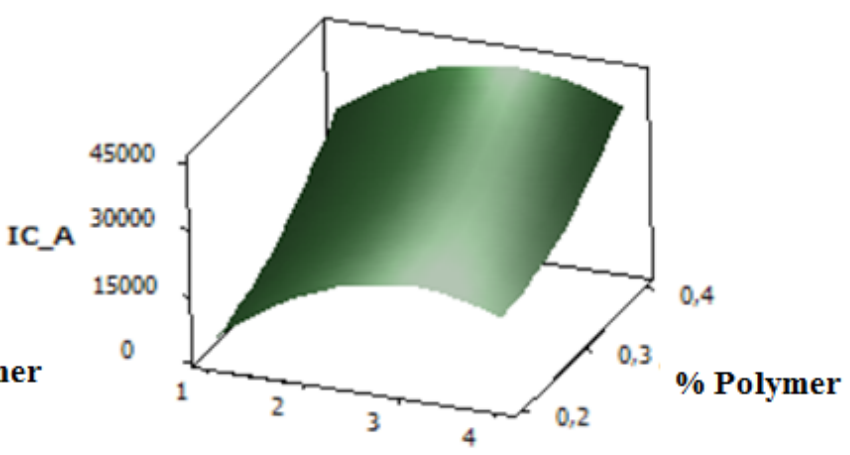

$\%$ Self-emulsifying wax

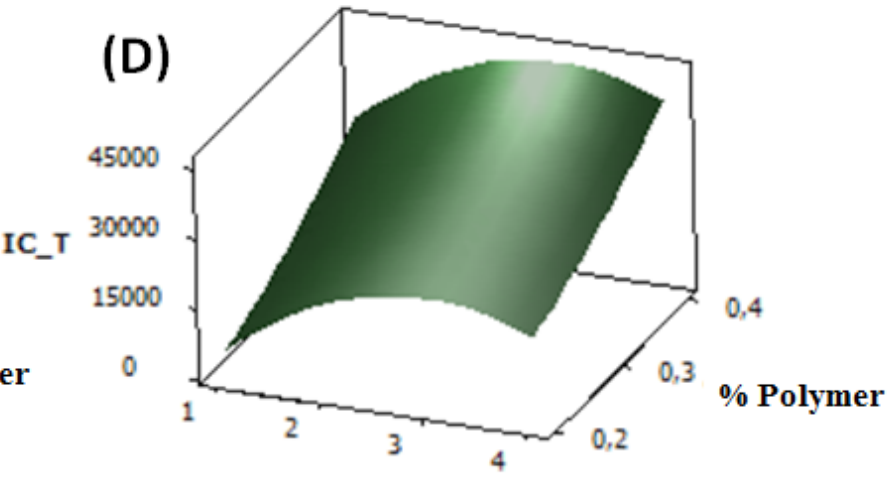

$\% \%$ Self-emulsifying wax

FIGURE 1 - Response surfaces for consistency index (CI) as a function of the factors: \% of self-emulsifying wax and \% hydrophilic polymer for the formulations: vehicle (A) containing $0.5 \%$ retinyl palmitate (B), $5 \%$ tocopheryl acetate (C) and $0.1 \%$ tocoretinate $(\mathrm{D})$.

\section{Statistical analysis for flow index (IF):}

Equations 6-9 represent the adjusted models obtained from statistical analysis that relates the response, flow index (IF), and the same significant encoded factors $\mathrm{X}_{1}$ and $\mathrm{X}_{2}$.

$$
\begin{aligned}
& \mathrm{IF}_{\mathrm{V}}=0,11667+0,0756 \mathrm{X}_{1+} 0,03979 \mathrm{X}_{1}^{2}+0,029792 \mathrm{X}_{2}^{2} \\
& \mathrm{IF}_{\mathrm{A}}=0,13+0,071875 \mathrm{X}_{1+} 0,035625 \mathrm{X}_{2}^{2} \\
& \mathrm{IF}_{\mathrm{E}}=0,13333+0,06 \mathrm{X}_{1}+0,027708 \mathrm{X}_{2}^{2} \\
& \mathrm{IF}_{\mathrm{T}}=0,12+0,072 \mathrm{X}_{1+} 0,045 \mathrm{X}_{2}^{2}
\end{aligned}
$$


The factor " $\%$ of self-emulsifying wax" affected linearly the response under study. On the other hand, quadratic positive effects were obtained for the "\% of hydrophilic polymer". The factor "proportion of nonionic surfactants" did not provide significant results for the response under analysis. In addition, for one of the formulations studied, the factor "Cetearyl Alcohol, Dicalcium Phosphate and Cetyl Phosphate 10 EO" had a quadratic negative effect (Figure 2).

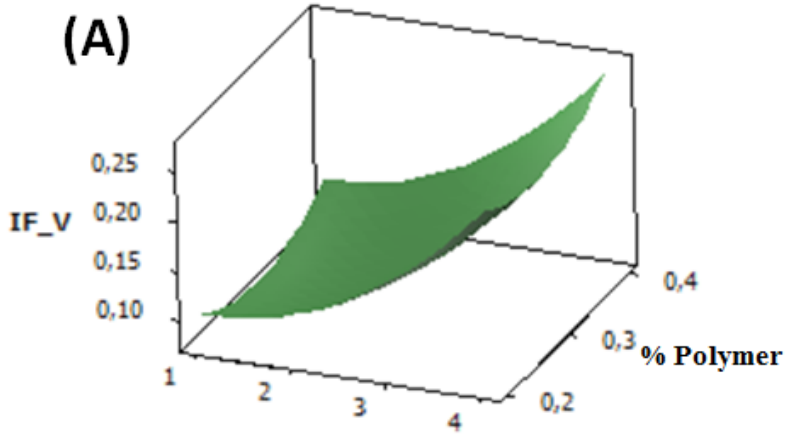

$\%$ Self-emulsifying wax

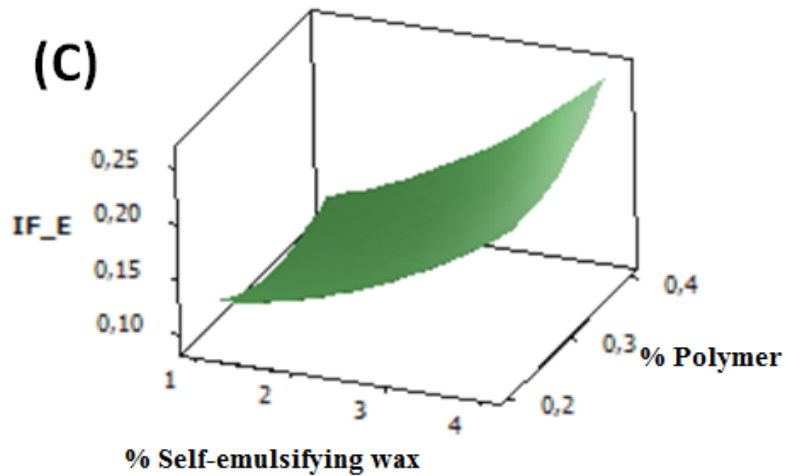

(B)

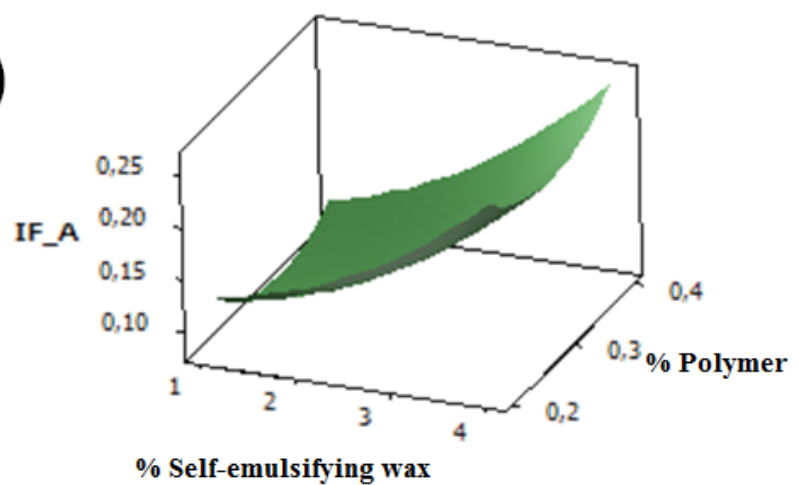

(D)

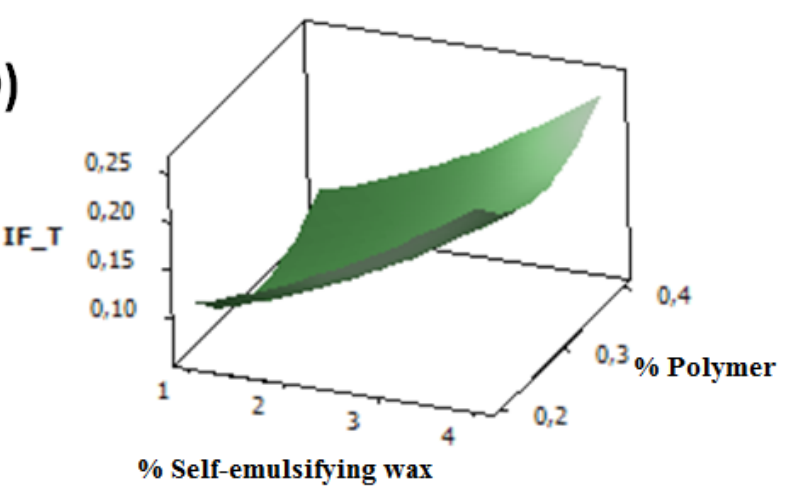

FIGURE 2 - Response surfaces for flow index (IF) as a function of the factors: \% of self-emulsifying wax and \% hydrophilic polymer for the formulations: vehicle (A) containing $0.5 \%$ retinyl palmitate (B), $5 \%$ tocopheryl acetate (C) and $0.1 \%$ tocoretinate (D).

\section{Statistical analysis for hysteresis area (AH)}

Equations 10-13 represent the adjusted models obtained from statistical analysis that relates the response, hysteresis area $(\mathrm{AH})$, and the significant encoded factors $\mathrm{X}_{1}$ and $\mathrm{X}_{2}$.

$\mathrm{AH}_{\mathrm{v}}=1977,80+1853,2 \mathrm{X}_{1+} 1600,32 \mathrm{X}_{2}$

$\mathrm{AH}_{\mathrm{A}}=2180+1843,1 \mathrm{X}_{1+} 1705,3 \mathrm{X}_{2}$
$\mathrm{AH}_{\mathrm{E}}=2886,09+1980 \mathrm{X}_{1+} 2038,99 \mathrm{X}_{2}$

$\mathrm{AH}_{\mathrm{T}}=2388,7+2197,3 \mathrm{X}_{1+} 1871,9 \mathrm{X}_{2}$

The factor "proportion of nonionic surfactants" did not provide significant results for the response under analysis. The factors $X_{1}$ and $X_{2}$ influenced in a linear and positive way the study response. Quadratic and interaction effects were not obtained for any variable in question (Figure 3). 
(A)



$\%$ Self-emulsifying wax

$\%$ Self-emulsifying wax



(B)

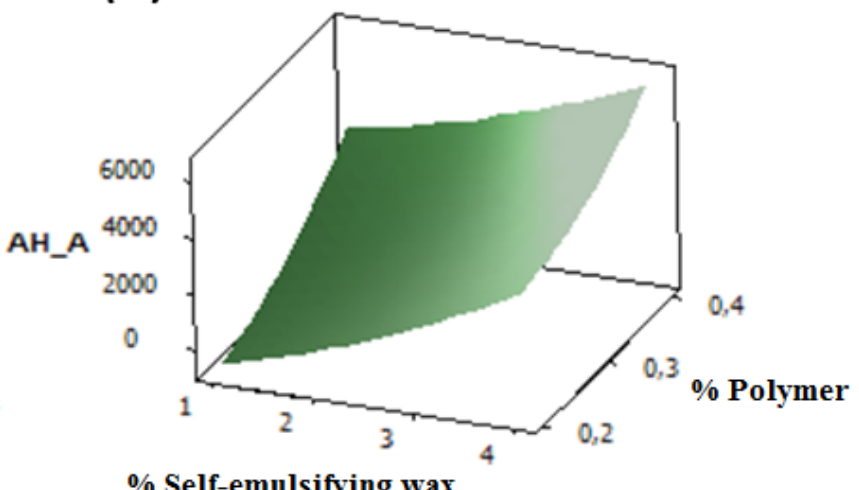

$\%$ Self-emulsifying wax



$\%$ Self-emulsifying wax

FIGURE 3 - Response surfaces for hysteresis area $(\mathrm{AH})$ as a function of the factors: \% of self-emulsifying wax and \% hydrophilic polymer for the formulations: vehicle (A) containing $0.5 \%$ retinyl palmitate (B), $5 \%$ tocopheryl acetate (C) and $0.1 \%$ tocoretinate $(\mathrm{D})$.

\section{Statistical analysis for minimum apparent viscosity (VAM)}

Equations 14 - 17 represent the adjusted models obtained from statistical analysis that relates the response, minimum apparent viscosity (VAM), and the significant encoded factors $\mathrm{X}_{1}$ and $\mathrm{X}_{2}$.

$\mathrm{VAM}_{\mathrm{V}}=793,13+479,90 \mathrm{X}_{1+} 371,27 \mathrm{X}_{2}+218,42 \mathrm{X}_{2}^{2}(14$

$\mathrm{VAM}_{\mathrm{A}}=798,55,7+441,66 \mathrm{X}_{1+} 337,91 \mathrm{X}_{2}+231,17 \mathrm{X}_{2}^{2}$
$\mathrm{VAM}_{\mathrm{E}}=969,98+381,9 \mathrm{X}_{1+} 422,33,1 \mathrm{X}_{2}-279,52 \mathrm{X}_{1}^{2}+$ $146,88 \mathrm{X}_{2}^{2}+181,464 \mathrm{X}_{1} \mathrm{X}_{2}$

$\operatorname{VAM}_{\mathrm{T}}=847,38+434,3 \mathrm{X}_{1+} 344,42 \mathrm{X}_{2}$

Positive linear effects were obtained for the factors $X_{1}$ and $X_{2}$. On the other hand, the factor "proportion of nonionic surfactants" had no significant effect on the response studied. Positive quadratic effects of $X_{2}$ were obtained for vehicle formulations containing vitamins $A$ and E. In addition, a positive interaction effect was observed between variables $\mathrm{X} 1$ and $\mathrm{X} 2$ for the formulation containing vitamin $\mathrm{E}$ (Figure 4). 



FIGURE 4 - Response surfaces for minimum apparent viscosity (VAM) as a function of the factors: \% of self-emulsifying wax and $\%$ hydrophilic polymer for the formulations: vehicle (A) containing $0.5 \%$ retinyl palmitate (B), $5 \%$ tocopheryl acetate (C) and $0.1 \%$ tocoretinate $(\mathrm{D})$.

\section{Statistical analysis for particle size (TP)}

Equation 18 represents the adjusted model obtained from statistical analysis that relates the response, particle size (TP), and the significant encoded factors $\mathrm{X}_{1}$ and $\mathrm{X}_{2}$.

$\mathrm{TP}=6,2581+2,3843 \mathrm{X}_{1}-1,6589 \mathrm{X}_{2}+1,6215 \mathrm{X}_{1}$ $-1,18529 \mathrm{X}_{1} \mathrm{X}_{2}$

Linear and quadratic positive effects were obtained for $\mathrm{X}_{1}$ and negative linear effect for $\mathrm{X}_{2}$. In addition, negative effects on the interaction between $\mathrm{X}_{1}$ and $\mathrm{X}_{2}$ were observed. Thus, it was assumed that the increase of the self-emulsifying wax concentration was related to the size of larger particles. On the other hand, the concentration of hydrophilic polymer collaborated in reducing the particle size of the formulation studied (Figure 5).

The increase in the concentration of the selfemulsifying wax and the hydrophilic polymer caused alterations on rheological behavior of the formulations: increase of the consistency index, flow index, hysteresis area and minimum apparent viscosity. Some studies have reported that the increase in the concentration of agents of consistency and polymeric rheological additives influenced the rheological parameters of the formulations (Calixto, Maia Campos, 2017; Calixto, Infante, Maia Campos, 2018; Gaspar, Maia Campos, 2003; Baby, 2009; Corrêa et al, 2005). This change in rheological parameters can modify formulation characteristics such as texture, spreadability and also clinical efficacy (Calixto et al., 2018). However, in the present study, with the used methods it was possible to evaluate the size of this effect in a concentration range, as well as the synergistic interaction, or not of the components of the formulation.

The increase in the concentration of self-emulsifying wax has led to a significant increase in particle size, this effect may be related to the increase of the concentration of substances present in the internal phase of the emulsion (oil phase) (Sepulveda, Kildsig, Ghaly, 2003). 


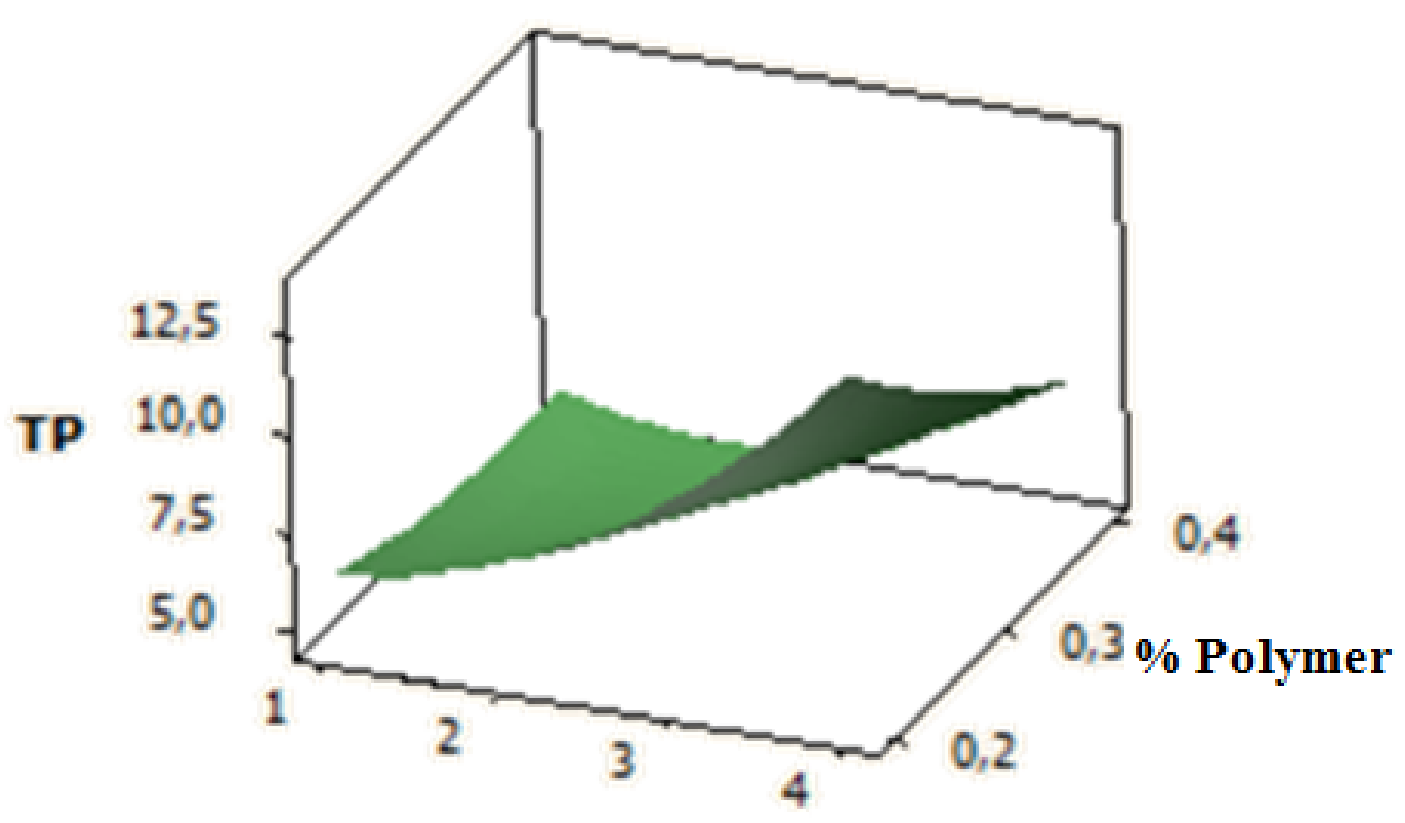

$\%$ Self-emulsifying wax

FIGURE 5 - Response surfaces for particle size (TP) as a function of the factors: $\%$ of self-emulsifying wax and $\%$ hydrophilic polymer for the formulation containing $0.1 \%$ tocoretinate.

On the other hand, the increase in hydrophilic polymer concentration led to the reduction of the particle size. The acrylates/C10-30 alkyl acrylate crosspolymer is a predominantly high molecular weight polyacrylic acid emulsifier. Its molecules have a small lipophilic portion and a large portion with hydrophilic affinity. This differentiated spatial configuration allows it to also acts as a primary emulsifier in oil-inwater type emulsions, besides being a viscosity-donor polymeric agent. This allows an increase in the density of the polymer network with emulsifying properties, and consequent reduction of the particle size (Fiume, Heldreth, Boyer, 2011; Tadros, 2006).

In synthesis, according to the results of the multivariate regression performed in the first phase of development, the main effects of cetearyl alcohol, dicetyl phosphate and cetyl phosphate 10 EO in the rheological parameters of the formulations were: increases on consistency index, flow index, hysteresis area, minimum apparent viscosity and particle size. The effects of the acrylates/C10-30 alkyl acrylate crosspolymer were: increases on consistency index, hysteresis area, minimum apparent viscosity and flow index. The proportion of steareth-21/steareth-2 surfactants did not present significant results in the studied parameters.

\section{Phase 2 - Second Box-Behnken factorial design analysis and completed results}

\section{Statistical analysis for rheological parameters}

It was not possible to fit a model correlating the factors studied and the responses to flow index and hysteresis area. Thus, none of the factors were significant for the responses. Equation 19 represents the adjusted model obtained from the statistical analysis that relates the response, Consistency Index (CI), and the significant factors coded $\mathrm{X}_{4}=\%$ of phytantriol of $\mathrm{e}$ $\mathrm{X}_{5}=\%$ of soy lecithin.

$\mathrm{IC}=27320+1264,9 \mathrm{X}_{4+} 2244,7 \mathrm{X}_{5}$

Linear effects were observed for the variables $\mathrm{X}_{4}$ and $\mathrm{X}_{5}$. No quadratic and interaction effects were observed for any of the variables (Figure 6). 


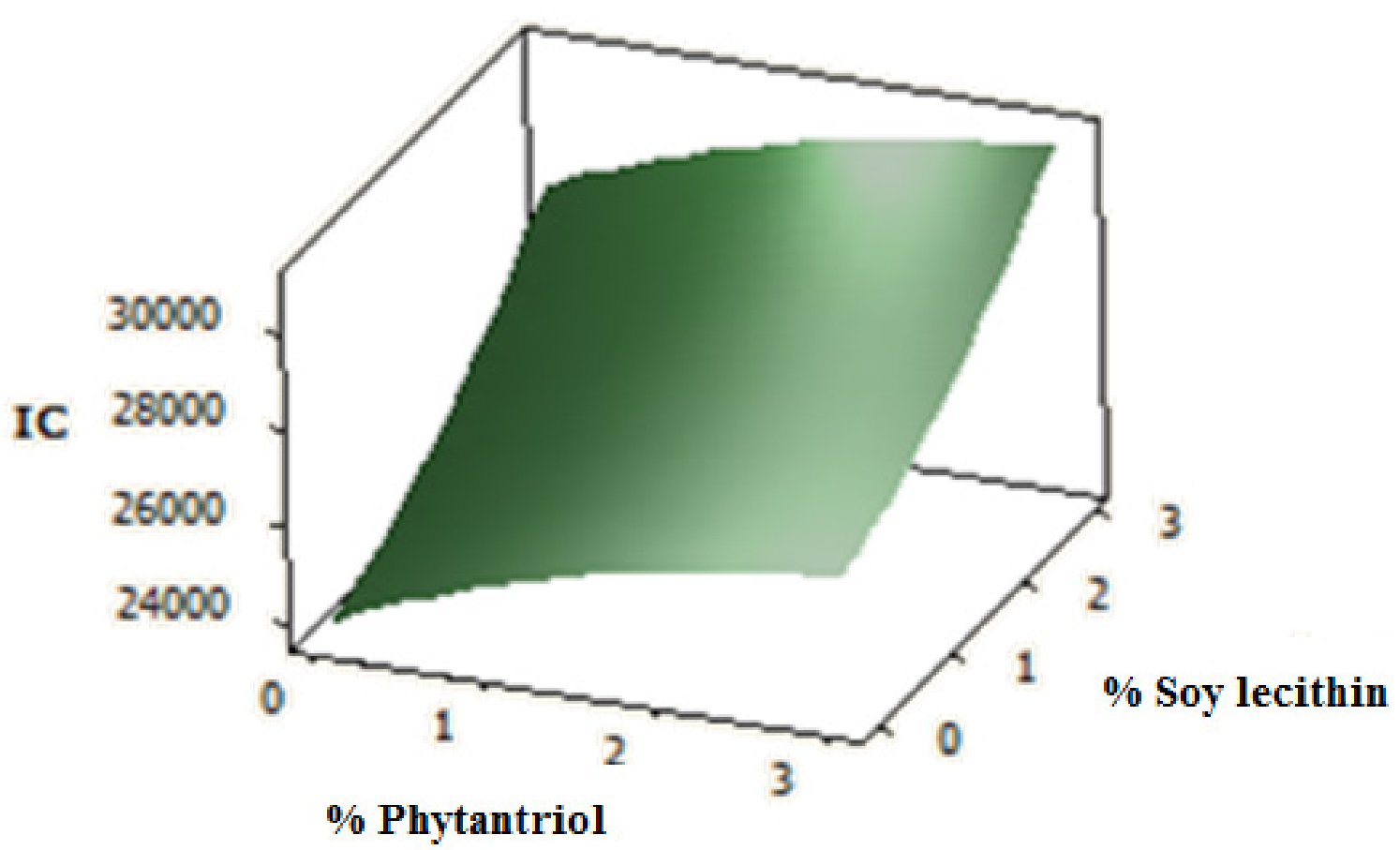

FIGURE 6 - Response surfaces for consistency index (CI) as a function of the factors: \% of phytantriol and \% of soy lecithin.

\section{Statistical analysis for sensorial analysis}

Equation 20 represents the adjusted model obtained from the statistical analysis that relates the response, stickiness $(\mathrm{P})$, and the significant encoded factors $\mathrm{X}_{4}$ $=\%$ of phytantriol, $X_{5}=\%$ of soy lecithin and ${ }_{6}=\%$ of caprylic/capric triglycerides.

$\mathrm{P}=3,0+0,81250 \mathrm{X}_{5-} 0,375 \mathrm{X}_{6+} 0,68750 \mathrm{X}_{4}^{2}-$ $0,56250 \mathrm{X}_{5}^{2}-0,65 \mathrm{X}_{4} \mathrm{X}_{5}$.

From equation 20 , it was observed that $X_{5}$ presented positive linear effects, and negative quadratic effects, although $\mathrm{X}_{6}$ had negative linear effects and variable $\mathrm{X}_{4}$ had negative quadratic effects. In addition, the variables $\mathrm{X}_{4}$ and $\mathrm{X}_{5}$ had negative interaction effects (Figure 7).
The addition of soy lecithin caused a significant increase in the oiliness $(\mathrm{O})$ of the formulation at the concentrations studied, phytantriol did not significantly influence this effect, on the other hand, the addition of caprylic/capric triglycerides reduced the oiliness of the formulation. Equation 21 represents the adjusted model obtained from the statistical analysis that relates the response and significant factors coded $\mathrm{X}_{4}, \mathrm{X}_{5}$ and $\mathrm{X}_{6}$.

$\mathrm{O}=2,66667+0,725 \mathrm{X}_{5}+0,74167 \mathrm{X}_{4}^{2}-1,10833 \mathrm{X}_{5}^{2}$

It was observed that "\% of soy lecithin" had positive linear effects, and negative quadratic effects. In addition, " $\%$ of phytantriol” had quadratic negative effects (Figure 8). 

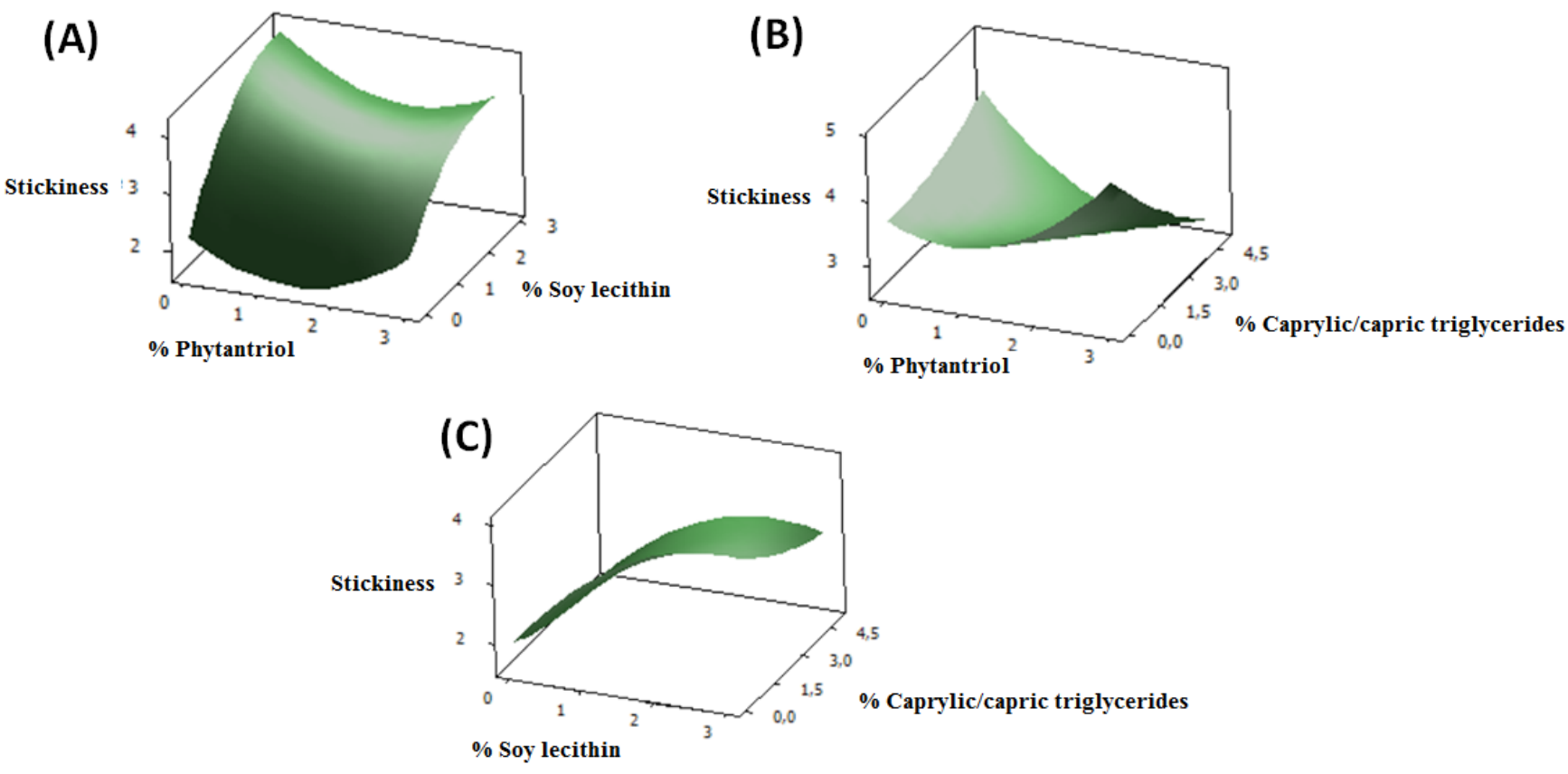

FIGURE 7 - Response surfaces for stickiness (P), as a function of the factors: \% phytantriol and \% of soy lecithin.
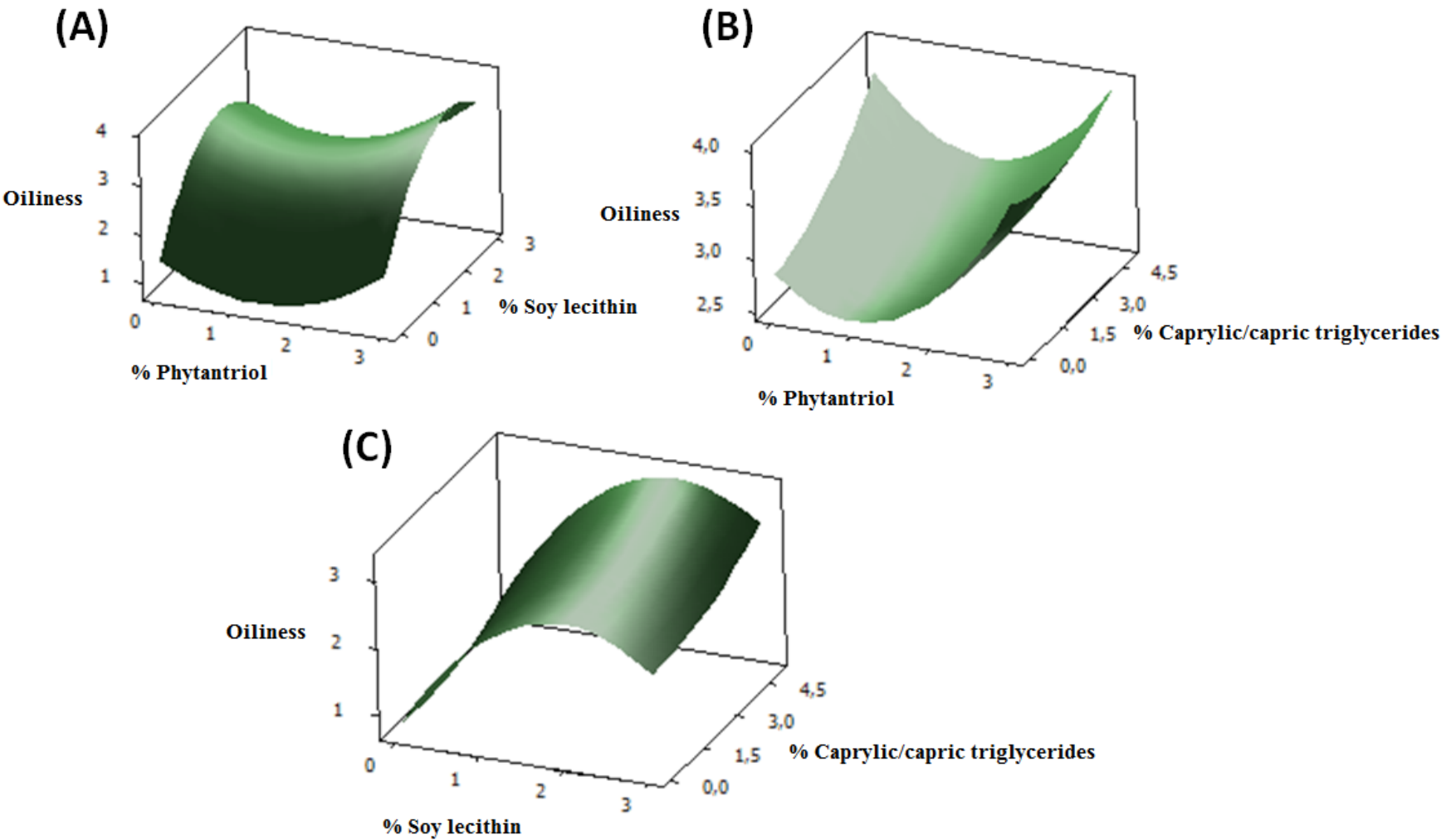

FIGURE 8 - Response surfaces for oiliness $(\mathrm{O})$, as a function of the factors: \% phytantriol and \% of soy lecithin. 


\section{Statistical analysis for moisturizing effect $(\mathrm{H})$}

Equation 22 represents the adjusted model obtained from the statistical analysis that relates the response, moisturizing effect, and the significant factors encoded $\mathrm{X}_{4}, \mathrm{X}_{5}$ and $\mathrm{X}_{6}$.

$\mathrm{H}=1,5+0,09354 \mathrm{X}_{5}$

Based on the obtained equation, only the factor $\mathrm{X}_{5}$, presented positive linear effect for the response (Figure 9).

The addition of soy lecithin had significant effects on the formulations in terms of increase in consistency index, in stickiness and in oiliness and also in improved the immediate moisturizing effects. Phytantriol showed effects on increasing consistency index and oiliness sensation. The addition of the emollients caprylic/capric triglycerides showed a modest reduction in stickiness of the formulations.

In the second phase of development, adjuvant substances were added with the purpose of improving the performance of the formulation. Some studies have shown that the composition of the vehicle can influence mechanical and physical properties of cosmetic formulations Serrão et al, 2018). Phytantriol is a substance used in cosmetic products for the skin and hair. It acts in the retention of cutaneous hydration and acts as an absorption promoter allowing greater penetration of lipophilic and hydrophilic substances into cosmetic formulations containing this raw material (Richert, Schrader, Schrader, 2003).

Several studies have used experimental design to evaluate the release of active substances (Baby et al, 2009) and to produce more efficient release systems for the cosmetic and dermatological area such as liposome production (Padamwar, Pokharkar, 2006), nanoparticles (Jung et al, 2013), nanoemulsions (Gutiérrez et al, 2008), among others.
The inclusion of sensory parameters in this phase, as well as the evaluation of hydration in the screening phase of the formulations using the proposed statistical tool, allowed to evaluate a greater range of factors and to provide technical and sensorial information. At the concentrations studied, phytantriol and soy lecithin showed an increase in the consistency index. Soy lecithin was the only raw material that presented increased moisturizing effect in the studied concentrations. Besides that, soy lecithin negatively impacted the sensorial, with the increase of the sensation of stickiness and oiliness of the skin. In the sensorial evaluation, it was possible to observe the interaction of the raw materials and their influence on the studied parameters. Isolated phytantriol showed a significant increase in the stickiness sensation, however, when associated with soy lecithin, there was a synergic effect that implied in reduction of stickiness. In addition, the emollient caprylic/capric triglycerides provided a reduction in stickiness.

Considering the research and development phase in development of cosmetics, several aspects should be considered in order to obtain the formulation with the desired characteristics. The results of this study open perspectives for the application of the technique of experiment planning in the phase of development of formulations, and screening process. Other factors can be equally studied, as texture and antioxidant properties, allowing a less empirical formulation development, and more based on quantitative measures.

In summary, the paper showed the importance of the application of experimental design with response surface methodology. With the developed protocol proposed in the present study made it was possible to obtain stable and optimized formulations with sensory adequate for the determined purposes. 


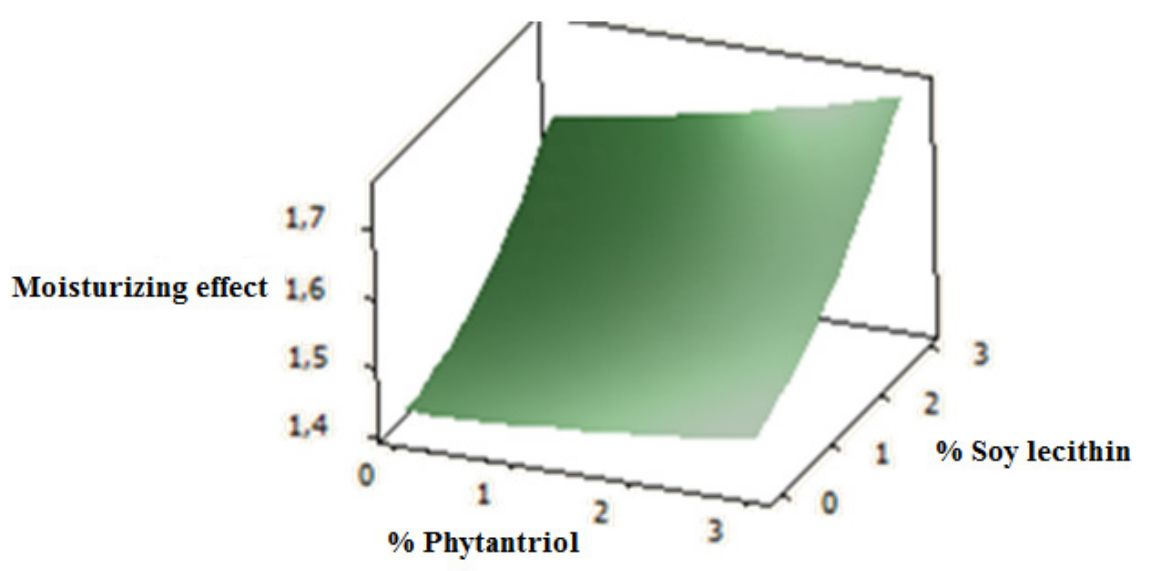

FIGURE 9 - Response surfaces for moisturizing effect $(\mathrm{H})$, as a function of the factors: \% phytantriol and \% of soy lecithin.

\section{CONCLUSION}

The factorial design of experiments, Box-Behnken method in response surface methodology, made possible to identify and quantify the influence of raw materials, as well as their interaction, on particle size, rheological parameters as consistency and flow index, hysteresis area and minimum apparent viscosity. In the second phase, the statistical design assisted to identify the influence of soy lecithin, phytantriol and caprylic/capric triglycerides on the consistency, stickiness and oiliness index and cutaneous hydration. Thus, the Box-Behnken design in response surface methodology proved to be an effective tool in cosmetics research and development, since it allowed the evaluation of the isolated effects as well as the interaction of raw materials in responses such as: rheological parameters, sensorial and clinical efficacy.

Considering that several aspects should be considered in order to obtain the formulation with the desired characteristics, the results of this study open perspectives for the application of the full factorial design of experiments in the research and development phase of formulations, and allowing for a less empirical formulation process, and more based on quantitative measures.

\section{ACKNOWLEDGEMENT}

The authors want to thank FAPESP - Fundação de Amparo à Pesquisa do Estado de São Paulo for financial support (FAPESP - 2014/26988-5).

\section{REFERENCES}

Baby AR, Haroutiounian-Filho CA, SarrufFD, Pinto CASDO, Kaneko TM, Velasco MVR. Influence of urea, isopropanol, and propylene glycol on rutin in vitro release from cosmetic semisolid systems estimated by factorial design. Drug Dev Ind Pharm. 2009;35(3):272-82.

Berthele H, Sella O, Lavarde M, Mielcarek C, Pense-Lheritier AM, Pirnay S. Determination of the influence of factors (ethanol, $\mathrm{pH}$ and a w) on the preservation of cosmetics using experimental design. Int J Cosmet Sci. 2014;36(1):54-61.

Calixto LS, Infante VHP, Maia Campos PMBG. Design and characterization of topical formulations: correlations between instrumental and sensorial measurements. AAPS PharmSciTech 2018;19: 1512.

Calixto LS, Maia Campos PMBG. Physical-Mechanical characterization of cosmetic formulations and correlation between instrumental measurements and sensorial properties. Int J Cosmet Sci. 2017;39(5):527-34.

Calixto LS, Maia Campos PMBG, Savary G, Picard C. Interactions between UV filters and active substances in emulsion: Effect on microstructure, physicochemical and invivo properties. Int J Pharm Sci. 2018;553(1-2):220-228.

Corrêa N, Júnior F, Ignácio, RF, Leonardi, GR Avaliação do comportamento reológico de diferentes géis hidrofílicos. Braz J Pharm Sci. 2005;41(1):73-8.

Costa-Machado ARM, Bastos JK, de Freitas LAP. Dynamic maceration of Copaifera langsdorffii leaves: A technological study using fractional factorial design. Brazilian J Pharmacogn. 2013;23(1):79-85. 
Djuris J, Vasiljevic D, Jokic S, Ibric S. Application of D-optimal experimental design method to optimize the formulation of $\mathrm{O} / \mathrm{W}$ cosmetic emulsions. Int $\mathrm{J}$ Cosmet Sci. 2014;36(1):79-87.

Edwards DJ, Mee RW. Fractional Box-Behnken designs for one-step response surface methodology. J Qual Technol. 2011;43(4):288

Ferreira SLC, Bruns RE, Ferreira HS, Matos GD, David JM, Brandão GC, et al. Box-Behnken design: An alternative for the optimization of analytical methods. Anal Chim Acta. 2007;597(2):179-86.

Fiume MM, Heldreth B, Boyer I. Crosslinked alkyl acrylates as used in cosmetics. Cosmetic Ingredient Review, p. 1-63, (2011). http://fibrosidus.com/wp-content/uploads/2015/07/ Crosslinked-Acrylates-Final-Safety-Assessment-2011.pdf

Gaspar LR, Maia Campos PMBG. Rheological behavior and the SPF of sunscreens. Int J Pharm. 2003;250(1):35-44.

Gianeti MD, Gaspar LR, De Camargo FB, Campos PMBGM. Benefits of combinations of vitamin $\mathrm{A}, \mathrm{C}$ and e derivatives in the stability of cosmetic formulations. Molecules. 2012;17(2):2219-30.

Gianeti MD, Mercurio DG, Campos PMBGM, Paulo S. The use of green tea extract in cosmetic formulations: not only an antioxidant active ingredient. Dermatol Ther. 2013;26(1): $267-71$.

Guaratini T, Gianeti MD, Campos PMBGM. Stability of cosmetic formulations containing esters of Vitamins $\mathrm{E}$ and A: Chemical and physical aspects. Int J Pharm. 2006;327(12):12-6.

Gutiérrez JM, González C, Maestro A, Solè I, Pey CM, Nolla J. Nano-emulsions: New applications and optimization of their preparation. Curr Opin Colloid Interface Sci. 2008;13(4): 245-51.

Jiao J, Burgess DJ. Rheology and stability of water-in-oil-inwater multiple emulsions containing Span 83 and Tween 80 . AAPS PharmSci. 2003;5(1):62-73.

Jung YJ, Truong NKV, Shin S, Jeong SH. A robust experimental design method to optimize formulations of retinol solid lipid nanoparticles. J Microencapsul. 2013;30(1):1-9.

Maia Campos PMBG, Gianeti MD, Mercurio DG, Gaspar LR. Synergistic effects of green tea and ginkgo biloba extracts on the improvement of skin barrier function and elasticity. J Drugs Dermatol. 2014 Sep;13(9):1092-7.

Manço LM, Mercurio DG, Melo MO, Campos PMBGM. Development of cosmetic formulations containing glucan polymer of cassava (Manihot esculenta): stability and sensory analisys. Biomed Biopharm Res. 2015;1(12):91-98.

Neto BB, Scarminio IS, Bruns RE. Como Fazer Experimentos-: Pesquisa e Desenvolvimento na Ciência e na Indústria. Bookman Editora; 2010.

Padamwar MN, Pokharkar VB. Development of vitamin loaded topical liposomal formulation using factorial design approach: Drug deposition and stability. Int J Pharm. 2006;320(1-2):37-44.

Pereira SV. Microstructured systems containing Chamomilla recutita L. extract for dermocosmetic applications. [Tese]. Ribeirão Preto (SP): Universidade de São Paulo; 2015. Available from: http://www.teses.usp.br/teses/ disponiveis/60/60137/tde-12052015-114418/pt-br.php

Richert S, Schrader A, Schrader K. Transdermal delivery of two antioxidants from different cosmetic formulations. Int $\mathrm{J}$ Cosmet Sci. 2003;25(1-2):5-13.

Sepulveda E, Kildsig DO, Ghaly ES. Relationship between internal phase volume and emulsion stability: The cetyl alcohol/stearyl alcohol system. Pharm Dev Technol. 2003;8(3):263-75.

Serrão, EC et al. Influence of different cosmetic vehicles in mechanical and physical properties of hair treated with oxidative hair dyes. Braz. J. Pharm. Sci. 2018;54(1):e17218.

Tacon LA, Freitas LAP. Box-Behnken design to study the bergenin content and antioxidant activity of Endopleura uchi bark extracts obtained by dynamic maceration. Brazilian J Pharmacogn. 2013;23(1):65-71.

Tadros T. Principles of emulsion stabilization with special reference to polymeric surfactants. J Cosmet Sci. 2006;57(2):153-69.

Wagemaker TAL, Silva SAM, Leonardi GR, Maia Campos PMBG. Green Coffea arabica L: Seed oil influences the stability and protective effects of topical formulations. Ind Crops Prod. 2015;63:34-40.

Received for publication on $05^{\text {th }}$ July 2018 Accepted for publication on $18^{\text {th }}$ April 2019 